\title{
Seabirds as environmental indicators: the advantages of combining data sets
}

\author{
Morten Frederiksen ${ }^{1,3, *}$, Roderick A. Mavor ${ }^{2}$, Sarah Wanless ${ }^{1}$ \\ ${ }^{1}$ Centre for Ecology and Hydrology, Hill of Brathens, Banchory AB31 4BW, UK \\ ${ }^{2}$ Joint Nature Conservation Committee, Dunnet House, 7 Thistle Place, Aberdeen AB10 1UZ, UK \\ ${ }^{3}$ Present address: National Environmental Research Institute, Dept. of Arctic Environment, University of Aarhus, \\ Frederiksborgvej 399, 4000 Roskilde, Denmark
}

\begin{abstract}
Breeding performance of seabirds reflects conditions in the marine environment, and seabirds are often considered suitable indicators because they are sensitive to variations in food supply and relatively easy to observe. However, any individual parameter (e.g. breeding success of a particular species at one site) may also be affected by drivers other than food supply, and selecting a suitable univariate indicator can be difficult, particularly if independent estimates of food availability on the appropriate scale are unavailable. We propose combining several data sets to overcome this limitation: if a given temporal pattern occurs for several parameters measured at one site, or for the same parameter measured at several sites, it is likely to reflect important spatiotemporal environmental variation, probably linked to food supply. Multivariate statistical techniques, such as principal component analysis (PCA), can be used to extract common signals from a number of intercorrelated time series. Examples from seabirds in the North Sea demonstrate that such common signals are correlated with physical and biological environmental variables. We propose a preliminary 'North Sea seabird index' and discuss how this index could be used in ecosystem-based management.
\end{abstract}

KEY WORDS: Ecological indicators $\cdot$ Seabirds $\cdot$ Food availability $\cdot$ Multivariate statistics $\cdot$ Principal component analysis

\section{INTRODUCTION}

There is a clear policy-driven need to develop reliable indicators of the ecological state of marine environments to support ecosystem-based management of living resources (Niemi et al. 2004, Rice \& Rochet 2005). While the final choice of indicators will be based on numerous criteria, including cost, practicality, etc., ecologists can play an important role in developing indicators that are both useful to managers and have a sound scientific basis. Seabirds may be useful in this process, as they are sensitive to variation in food supply, relatively easy to study and have a high public profile (e.g. Bost \& le Maho 1993, Montevecchi 1993). However, selecting appropriate indicator variables is not straightforward, since ideally they should fulfil several potentially conflicting criteria, such as (1) be easily measured, (2) be sensitive to stresses on the system and respond in a predictable manner, (3) be integrative, and (4) have low variability in response (Dale \& Beyeler 2001). In addition, indicators should be reasonably easy for decision makers and the general public to interpret, and preferably relevant for resource management policy. The relative weighting of these criteria will depend on whether it is primarily aimed at indicating the general health of an aspect of the environment, or tailored to reflect a specific aspect or the response to a specific stressor.

Suggested or implemented seabird-based indicators usually include single variables measured at one site or summed over a defined area. For example, the proportion of oiled birds among common guillemots Uria aalge found dead on North Sea beaches has been adopted as an 'Ecological Quality Objective' by the OSPAR Commission for the Protection of the Marine Environment of the North-East Atlantic (Rogers \& Greenaway 2005). Such univariate indicators are often easy to measure and interpret, thus fulfilling some of 
the critical requirements. However, their sensitivity to stresses is often unknown, and it is not always obvious that they are integrative, i.e. reflect a general response of the ecosystem to natural or anthropogenic stressors. Alternatively, by combining several data sets using, e.g., multivariate statistics, it is possible to develop integrative indicators showing predictable responses to stressors, although data requirements are substantially higher and ease of interpretation may be compromised. This approach is common in freshwater systems (e.g. O'Connor et al. 2000), but has seldom been used in marine contexts to date, with the notable exception of the Combined Standardised Index developed by the British Antarctic Survey based on data from long-term studies of seabirds and pinnipeds on Bird Island, South Georgia (Boyd \& Murray 2001, Reid et al. 2005).

Here, we use long-term seabird data sets from the NW North Sea to explore the feasibility and potential advantages of combining data across species and/or sites. First, we validate this approach by testing whether correlations between time series are sufficiently high to make combining them an attractive option and whether such combined indices are as responsive to environmental conditions as are individual time series. Second, we propose a preliminary combined index of the breeding performance of 5 seabird species in this area as a general indicator of the 'health' of the marine ecosystem, in terms of providing sufficient food for breeding seabirds to raise their young.

\section{MATERIALS AND METHODS}

Combining data. Related ecological time series, e.g. breeding productivity of several seabird species in the same area, are often moderately to highly intercorrelated. This presumably reflects a common dependence on environmental conditions, such as weather or a shared food supply. In addition, each time series may be affected by measurement error as well as idiosyncratic factors, such as varying predation levels at some sites or higher sensitivity of one species to weather. By combining the data sets to extract a common signal, it is possible to identify the general response of a species or community to environmental variation, independent of these variable-specific issues. In the rare case when correlations between time series are very low, indicating no general response, there are no gains associated with combining the data sets. The choice of methods for combining several data sets (ecological time series) depends on the nature of the data. If data are roughly normally distributed and all data series are similar in terms of measurement scale and variability, e.g. the breeding productivity of a particular species measured at several sites, then the arithmetic mean provides a simple and useful summary. Appropriate link functions and error distributions can be used to account for nonnormal data, if needed. In the case of unbalanced designs with missing data points, least-squares means from a model with year effects only give adjusted means as if the design had been balanced. Some data sets and/or annual values may be considered more reliable than others, e.g. if they are based on larger sample sizes; in this case, appropriate weights can be used when estimating the mean.

When data are more complex, such as when measurement scales and/or variability differ substantially, multivariate techniques must be applied (McGarigal et al. 2000). Several approaches are possible, but here we concentrate on principal component analysis (PCA), which provides an objective method for extracting the strongest possible common signal from a number of intercorrelated time series. Individual principal components are uncorrelated, and thus potentially represent different aspects of seabirds' responses to the environment. Important diagnostics of PCA include proportions of the total variation explained by each component and correlations between components and original variables (often termed loadings). Standard multivariate techniques, including PCA, do not allow for missing data. In such cases, missing values can be imputed, i.e. replaced by best guesses or specific methods that allow for missing data developed (e.g. Boyd \& Murray 2001).

Validating the data combination approach. First, we tested whether the relationship between breeding productivity of black-legged kittiwakes Rissa tridactyla, sea surface temperature (SST) and fishery was consistent between colonies within a region. Breeding productivity (number of fledged chicks per nest built) of kittiwakes on the Isle of May, SE Scotland, is strongly negatively related to late winter SST in the previous year and to the presence of an industrial (fishmeal) fishery for lesser sandeels Ammodytes marinus, the main prey during the breeding season (Frederiksen et al. 2004). Kittiwake breeding productivity has also been monitored under the UK Seabird Monitoring Programme at 6 other colonies in the same region of the NW North Sea (E Scotland and NE England; Fig. 1), as defined by sandeel population structure and correlations between kittiwake breeding productivity time series (Frederiksen et al. 2005, Mavor et al. 2005). We repeated the analysis of Frederiksen et al. (2004) for the Isle of May and these other colonies, as well as for the mean breeding productivity in the region, based on data from 1986 to 2004. The fishery was scored as present in 1991 to 1998, and mean February/ March SSTs from this region were obtained from the German Bundesamt für Seeschifffahrt und Hydrographie (www.bsh.de). 


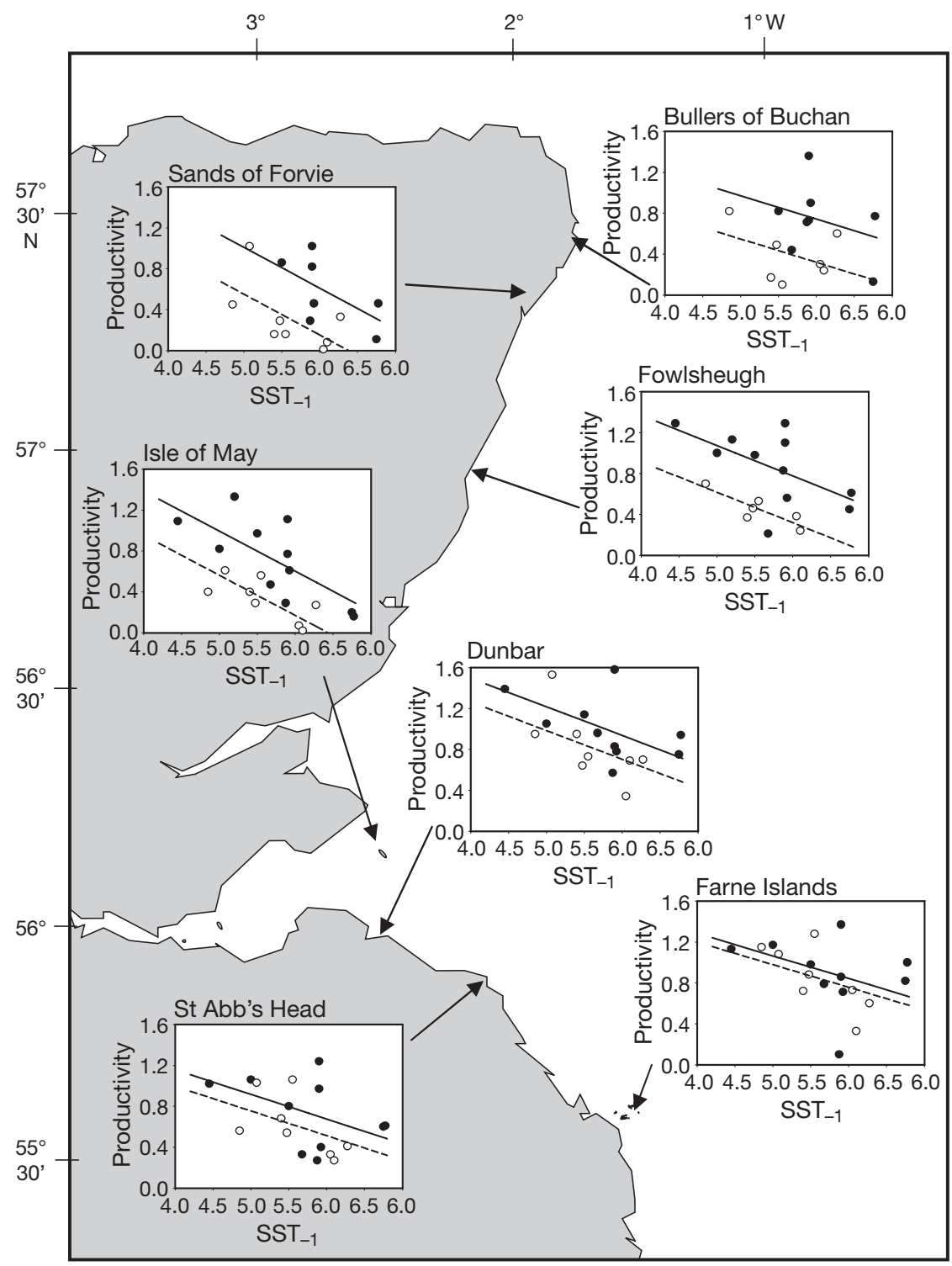

Fig. 1. Rissa tridactyla. Breeding productivity (number of fledged chicks per nest) of black-legged kittiwakes at 7 colonies in the NW North Sea, as related to local late winter sea surface temperature (SST) in the previous year in ${ }^{\circ} \mathrm{C}\left(\mathrm{SST}_{-1}\right)$ and the presence of a sandeel fishery, 1986 to 2004. Regression lines from a model with no interaction between fishery and $\mathrm{SST}_{-1}$. Solid lines and $\bullet$ : non-fishery years; dashed lines and o: fishery years. Details of the regressions in Table 1

Second, we tested whether the relationship between seabird breeding productivity and larval sandeel abundance was consistent between species at one site. Data on annual breeding productivity (number of fledged chicks per nest) of 4 sandeel-dependent seabird species (European shag Phalacrocorax aristotelis, black-legged kittiwake, razorbill Alca torda, Atlantic puffin Fratercula arctica) were collected using standardised methods on the Isle of May from 1986 to 2003 (Harris et al. 2005); there were no missing values in any of these data sets. Although common guillemots also mainly feed their chicks on sandeels, we did not include this species as adults carry single fish back to their offspring, and breeding productivity is consequently more tightly linked to size and quality of prey rather than abundance (Frederiksen et al. 2006). An index of larval sandeel abundance, standardised to 1 May, was estimated from the prevalence, abundance and size of sandeel larvae in Continuous Plankton Recorder samples from the NW North Sea (see Frederiksen et al. 2006 for details). Preliminary analyses showed that the value of the larval sandeel index in the previous year was more closely related to seabird breeding productivity than the same year's value, indicating a dependence on 1-yr-old (1-group) sandeel (authors' unpubl. data). We carried out a PCA on the 4 breeding productivity time series, and modelled the first principal component (PC1) as well as the 4 original time series as functions of the lagged sandeel index using linear regression. The PCA was performed on the correlation matrix of the original time series, thus implicitly standardising data to zero mean and unit variance.

A preliminary North Sea seabird index. To develop a general index of seabird breeding performance in the NW North Sea, we combined data from all regularly monitored species on the Isle of May. Data collection at this colony is much more comprehensive than at any other colony in the region, and for blacklegged kittiwake the correlation with the regional mean was also highest here (see 'Results'). Breeding productivity was measured for European shag, black-legged kittiwake, common guillemot, razorbill and Atlantic puffin as described above from 1986 to 2005. For common guillemot and Atlantic puffin, the mean mass of near-fledged chicks was also recorded. Again, there were no missing values in any of the data sets. We carried out a PCA on these 7 response variables using the same approach as above, retaining the first 2 principal components (PC1 and PC2). 


\section{RESULTS}

\section{Kittiwakes, SST and fishery}

Data from each of the 7 colonies in the study region were available for 15 to $19 \mathrm{yr}$ during 1986 to $2004 ; 13$ data points $(10 \%)$ were missing. Breeding productivities of kittiwakes in the study colonies were highly positively intercorrelated (mean $r=0.66$, all $r>0.28$, all $\mathrm{p} \leq 0.30,17$ of $21 \mathrm{p}<0.05, \mathrm{n}=13$ to $18 \mathrm{yr}$ ), as also found by Frederiksen et al. (2005) using shorter time series. An ANOVA model weighted by annual sample size with only year effects explained $63 \%$ of the total variation; least-squares means estimated from this model were highly positively correlated with raw data from each colony ( $r=0.66$ to 0.96 , all $\mathrm{p}<0.01$ ), with highest correlation for the Isle of May. Late winter SST lagged by $1 \mathrm{yr}$ together with the presence of a sandeel fishery explained 18 to $66 \%$ of the annual variation in breeding productivity at individual colonies, and model coefficients were similar across colonies, particularly for the SST effect (Table 1, Fig. 1). The same 2 factors were highly significantly related to the regional leastsquares mean and explained $61 \%$ of the annual variation (Table 1), only slightly lower than the highest value for an individual colony, the Isle of May.

\section{Seabird breeding productivity and larval sandeel abundance}

Breeding productivities of the 4 species were mainly positively correlated $(r=-0.16$ to $0.65,1$ of $6 p<0.05$, $\mathrm{n}=18 \mathrm{yr}$ ). PC1 explained $51 \%$ of the total inter-annual variation in breeding productivity, and loadings were high and positive for all original time series (Table 2). Breeding productivity was significantly positively associated with the sandeel larval index for European
Table 2. Linear regressions of breeding productivity of 4 seabirds on Isle of May, and of their first principal component (PC1), against an index of larval sandeel Ammodytes marinus abundance in the previous spring, 1986 to 2003. Loadings of the 4 original time series on the PC1 are also given. Note that coefficients are not directly comparable

\begin{tabular}{|lclrc|}
\hline Species & Coefficient & $\mathrm{p}$ & $\mathrm{R}^{2}$ & Loading \\
\hline European shag & 0.1383 & 0.015 & $32 \%$ & 0.50 \\
Black-legged kittiwake & 0.1152 & 0.017 & $31 \%$ & 0.86 \\
Razorbill & 0.0076 & 0.49 & $3 \%$ & 0.51 \\
Atlantic puffin & 0.0162 & 0.26 & $8 \%$ & 0.89 \\
PC1 & 0.4119 & 0.022 & $29 \%$ & - \\
\hline
\end{tabular}

shag and black-legged kittiwake, but not for razorbill and Atlantic puffin (Table 2, Fig. 2). PC1 was also significantly correlated with the sandeel index, with a slightly lower proportion of variation explained than for shags and kittiwakes (Table 2, Fig. 3).

\section{A preliminary North Sea seabird index}

All correlations between the 7 response variables were positive $(\mathrm{r}=0.05$ to $0.84,11$ of $21 \mathrm{p}<0.05, \mathrm{n}=$ 20 yr). PC1 explained $57 \%$ of the total variation, with positive loadings for all original variables, 5 of 7 above 0.75 (Table 3). PC2, which explained 19\% of the total variation, was mainly positively associated with European shag and black-legged kittiwake breeding productivity (Table 3). PC1 showed a clear declining trend over the study period (Fig. $4 ; \mathrm{R}^{2}=$ $48 \%, p=0.0007$ ), whereas PC2 showed an increasing trend after 1990, the trend approaching statistical significance for the whole study period (Fig. $4 ; R^{2}=19 \%$, $\mathrm{p}=0.057)$.
Table 1. Rissa tridactyla. Results from general linear models relating blacklegged kittiwake breeding productivity to the presence of a sandeel Ammodytes marinus fishery and local late winter SST in the previous year $\left(\mathrm{SST}_{-1}\right)$, for 7 colonies in the NW North Sea and the regional mean, 1986 to 2004. Locations of colonies are shown in Fig. 1

\begin{tabular}{|c|c|c|c|c|c|c|}
\hline \multirow[t]{2}{*}{ Colony } & \multirow[t]{2}{*}{$\mathrm{n}$} & \multicolumn{2}{|c|}{ — Fishery — } & \multicolumn{2}{|c|}{$-\mathrm{SST}_{-1}-$} & \multirow[t]{2}{*}{$\mathrm{R}^{2}$} \\
\hline & & Coefficient & $\mathrm{t} p$ & Coefficient & $\mathrm{t} p$ & \\
\hline Bullers of Buchan & 15 & -0.4274 & 0.028 & -0.2279 & 0.22 & $35 \%$ \\
\hline Sands of Forvie & 15 & -0.4584 & 0.013 & -0.3993 & 0.020 & $47 \%$ \\
\hline Fowlsheugh & 17 & -0.4575 & 0.003 & -0.2970 & 0.013 & $57 \%$ \\
\hline Isle of May & 19 & -0.4327 & 0.001 & -0.3919 & 0.0006 & $66 \%$ \\
\hline Dunbar & 18 & -0.2325 & 0.11 & -0.2795 & 0.025 & $35 \%$ \\
\hline St Abb's Head & 18 & -0.1629 & 0.26 & -0.2411 & 0.057 & $25 \%$ \\
\hline Farne Islands & 18 & -0.0862 & 0.57 & -0.2213 & 0.095 & $18 \%$ \\
\hline Regional mean & 19 & -0.3222 & 0.0035 & -0.3155 & 0.001 & $61 \%$ \\
\hline
\end{tabular}

\section{DISCUSSION}

We found that response variables, whether breeding productivity of one species measured at several sites, or breeding performance of several species measured at one site, tended to be well correlated. Data could therefore profitably be combined to identify common signals (regional means or principal components), which in turn were highly positively correlated with the original time series.

The 2 case studies with environmental covariates show that combining data sets resulted in little or no loss in terms of the strength of relationships with relevant environmental parameters (Tables 1 \& 2). 


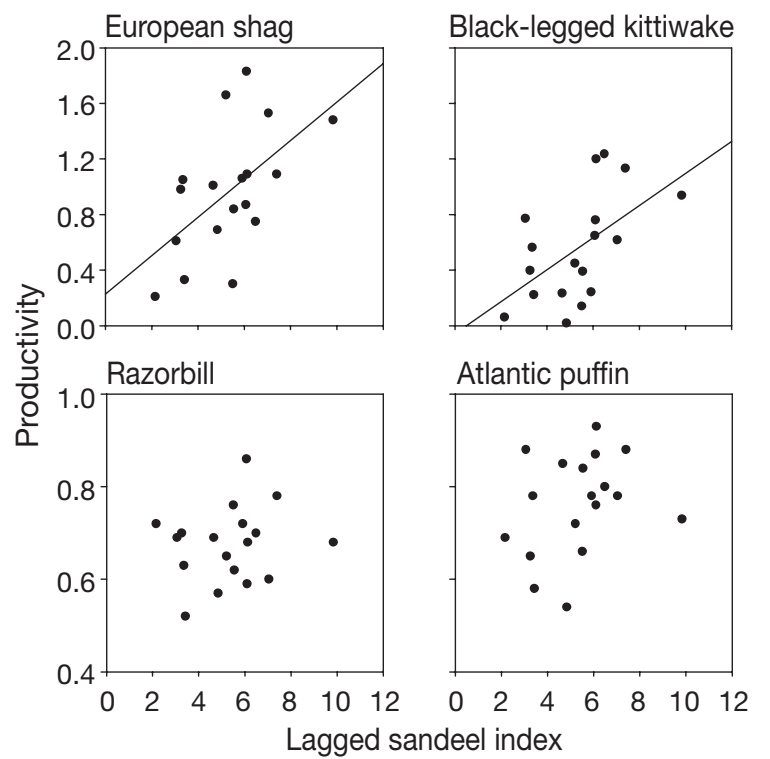

Fig. 2. Breeding productivity (number of fledged chicks per nest) of 4 seabird species at the Isle of May as related to an index of larval sandeel abundance in the previous spring, 1986 to 2003. Regression lines are shown for significant relationships (see Table 2 for details)

There were also substantial gains in terms of generality. We conclude that black-legged kittiwake breeding productivity at several colonies in the NW North Sea was negatively correlated with late winter temperatures and the presence of a sandeel fishery, and that breeding productivity of sandeel-dependent seabirds on the Isle of May was positively related to the abundance of sandeel larvae in spring of the previous year. This is an important first step in testing whether multivariate seabird indicators can provide useful information about the marine environment.

Combining data also aids identification of the most relevant univariate indicators, which often can be

Table 3. The first 2 principal components of 7 breeding performance variables of seabirds breeding on the Isle of May, 1986 to 2005. Loadings for each variable and the proportion of the total variance explained by each component are given

\begin{tabular}{|llc|}
\hline Variable & \multicolumn{2}{c|}{ Principal components } \\
& PC1 & PC2 \\
\hline Proportion explained & $57 \%$ & $19 \%$ \\
Breeding productivity & & \\
European shag & 0.40 & 0.69 \\
Black-legged kittiwake & 0.53 & 0.63 \\
Common guillemot & 0.84 & -0.42 \\
Razorbill & 0.75 & -0.41 \\
Atlantic puffin & 0.85 & 0.24 \\
Fledging mass & & \\
Common guillemot & 0.92 & -0.13 \\
Atlantic puffin & 0.84 & -0.04 \\
\hline
\end{tabular}

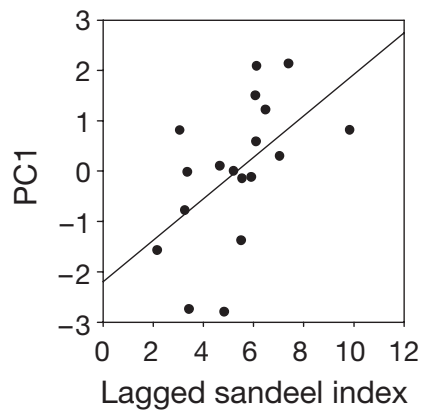

Fig. 3. Breeding productivity (number of fledged chicks per nest) of 4 seabird species at the Isle of May as related to an index of larval sandeel abundance in the previous spring, 1986 to 2003. Regression line indicates a significant relationship

(see Table 2 for details). PC1: first principal component

measured at lower cost and are potentially applicable to large-scale, extensive monitoring programmes. The analysis of black-legged kittiwake breeding productivity at 7 colonies in the NW North Sea showed that data from the Isle of May had the highest correlation with the regional mean $(r=0.96)$, and that the relationships with SST and fishery were strongest for this colony (Table 1). The colony could thus be regarded as the most appropriate location to monitor black-legged kittiwake breeding productivity in this region. Similarly, black-legged kittiwake or European shag would be the most appropriate species to monitor if the aim was to study the relationship between breeding productivity and the abundance of sandeel larvae (Table 2), and mean fledging mass of common guillemot chicks would provide an excellent proxy for the breeding performance of 5 seabird species on the Isle of May (Table 3).

The proposed North Sea seabird index showed some interesting patterns (Fig. 4). PC1, which describes demographic performance of all species with an emphasis on the 3 alcids (Table 3 ), showed a clear decline over the $20 \mathrm{yr}$ study period, presumably indicating a general deterioration of conditions during the breeding season around the Isle of May. Interpretation of PC2 is more complex, as the 2 variables with the highest loading, European shag and black-legged kittiwake breeding productivity, also load positively on PC1 (Table 3). The positive trend since 1990 (Fig. 4) thus implies that, relative to the alcids, these 2 species have done better in recent years, even though kittiwake breeding productivity has declined over the study period when viewed in isolation (cf. Frederiksen et al. 2004).

Ecological indicators have at least 2 different aims. They may either serve to indicate the general state or 'health' of an ecosystem, or they may measure the response of organisms to a specific stressor. The pro- 


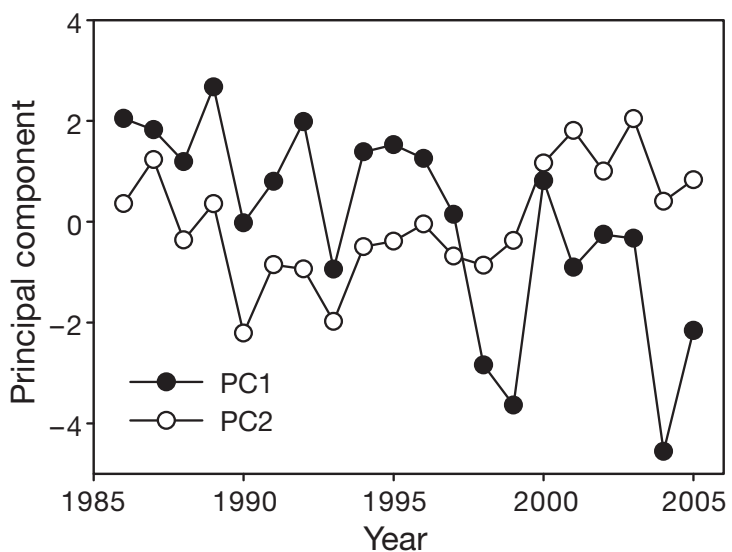

Fig. 4. The first 2 principal components (PC1 and PC2) of 7 seabird breeding performance variables at the Isle of May, 1986 to 2005. Variables included are breeding productivity of 5 species and mean fledging mass of 2 species (see Table 3 )

posed North Sea seabird index belongs to the first class of indicators. PC1 shows a pronounced decline in conditions for seabirds in this region over the last $20 \mathrm{yr}$, but we do not know precisely how the decline is expressed. It is very likely that changes in food supply and, specifically, in the availability and nutritional quality of the main prey (lesser sandeels) are related to this decline, but in itself the index does not show this. Seabird-based monitoring has previously shown that lesser sandeels in this region have diminished substantially in size over a $30 \mathrm{yr}$ period (Wanless et al. 2004). Despite the non-specific nature of this index, we argue that it can serve to highlight an aspect of the general health of the local pelagic ecosystem, namely its ability to supply breeding seabirds with sufficient highquality food to successfully raise their young. Given that direct monitoring of lesser sandeel abundance is both expensive and technically difficult (Greenstreet et al. 2006), using indicators based on the performance of highly visible sandeel-dependent, land-based predators is an attractive option. PCA extracts the strongest possible common signal from a number of correlated ecological time series, and is thus an appropriate method for identifying such a non-specific indicator. On the other hand, if the aim is to develop a more specific indicator, it needs to be validated with relevant environmental data. Alternative multivariate methods, such as canonical correlation analysis (McGarigal et al. 2000) or canonical correspondence analysis (Lepš \& Šmilauer 2003), can be used to identify an optimal linear combination of data, maximising the correlation with one or more environmental time series. This combination can then be used as an indicator of this specific aspect of the environment.

One of the most important functions of marine ecological indicators in the near future will be to support the developing concept of ecosystem-based resource management (Browman \& Stergiou 2004, Jennings 2005). To do this, indicators need to provide reliable measures of the health of the ecosystem, so that the consequences of changes in management practice can be monitored and assessed (Niemi \& McDonald 2004). An integrative approach is therefore needed. This can be achieved by selecting either a suite of univariate indicators, which together cover the various facets of the ecosystem, or a smaller number of multivariate indicators, each of which summarises the response of a major ecosystem component. In well-studied marine systems, such as the North Sea, the number of potential univariate indicators is huge, and there is substantial scope for simplification by applying suitable multivariate techniques. Multivariate indicators need not be constrained by taxonomical boundaries, but should rather reflect functional categories or guilds. As an example, the seabird index suggested here could be extended to cover all homeothermic land-based marine predators, i.e. including pinnipeds (cf. Boyd \& Murray 2001, Reid et al. 2005). Future research should aim at developing robust, integrative indicators of marine systems, and multivariate techniques have an important part to play in this process.

Acknowledgements. We are grateful to everyone who collected kittiwake data as part of the UK Seabird Monitoring Programme, and to M. P. Harris and everyone else who collected seabird data on the Isle of May. Thanks to F. Daunt for producing the map, to J. B. Reid, M. Parsons, S. Hatch and 2 anonymous referees for valuable comments, and to W. J. Sydeman and J. F. Piatt for inviting M.F. to the 'Seabirds as Indicators' symposium at the Pacific Seabird Group meeting, Girdwood, Alaska, in February 2006.

\section{LITERATURE CITED}

Bost CA, le Maho Y (1993) Seabirds as bio-indicators of changing marine ecosystems: new perspectives. Acta Oecol 14:463-470

Boyd IL, Murray AWA (2001) Monitoring a marine ecosystem using responses of upper trophic level predators. J Anim Ecol 70:747-760

Browman HI, Stergiou KI (eds) (2004) Theme section: perspectives on ecosystem-based approaches to the management of marine resources. Mar Ecol Prog Ser 274:269-303

Dale VH, Beyeler SC (2001) Challenges in the development and use of ecological indicators. Ecol Indic 1:3-10

Frederiksen M, Wanless S, Harris MP, Rothery P, Wilson LJ (2004) The role of industrial fisheries and oceanographic change in the decline of North Sea black-legged kittiwakes. J Appl Ecol 41:1129-1139

Frederiksen M, Wright PJ, Harris MP, Mavor RA, Heubeck M, Wanless S (2005) Regional patterns of kittiwake Rissa tridactyla breeding success are related to variability in sandeel recruitment. Mar Ecol Prog Ser 300:201-211

Frederiksen M, Edwards M, Richardson AJ, Halliday NC, Wanless S (2006) From plankton to top predators: bottomup control of a marine food web across four trophic levels. J Anim Ecol 75:1259-1268 
Greenstreet SPR, Armstrong E, Mosegaard H, Jensen H and others (2006) Variation in the abundance of sandeels Ammodytes marinus off southeast Scotland: an evaluation of area-closure fisheries management and stock abundance assessment methods. ICES J Mar Sci 63:1530-1550

Harris MP, Wanless S, Murray S, Mackley E (2005) Isle of May seabird studies in 2004. JNCC Report No. 375, JNCC/CEH, Peterborough/Banchory

Jennings S (2005) Indicators to support an ecosystem approach to fisheries. Fish Fish 6:212-232

Lepš J, Šmilauer P (2003) Multivariate analysis of ecological data using CANOCO. Cambridge University Press

Mavor RA, Parsons M, Heubeck M, Schmitt S (2005) Seabird numbers and breeding success in Britain and Ireland, 2004. UK Nature Conservation Report No. 29, Joint Nature Conservation Committee, Peterborough

McGarigal K, Cushman S, Stafford S (2000) Multivariate statistics for wildlife and ecology research. Springer, New York

Montevecchi WA (1993) Birds as indicators of change in marine prey stocks. In: Furness RW, Greenwood JJD (eds) Birds as monitors of environmental change. Chapman \& Hall, London, p 217-266

Editorial responsibility: Howard Browman (Associate Editorin-Chief), Storebø, Norway
Niemi GJ, McDonald ME (2004) Application of ecological indicators. Annu Rev Ecol Evol Syst 35:89-111

Niemi G, Wardrop D, Brooks R, Anderson S and others (2004) Rationale for a new generation of indicators for coastal waters. Environ Health Perspect 112:979-986

O'Connor RJ, Walls TE, Hughes RM (2000) Using multiple taxonomic groups to index the ecological condition of lakes. Environ Monit Assess 61:207-228

Reid K, Croxall JP, Briggs DR, Murphy EJ (2005) Antarctic ecosystem monitoring: quantifying the response of ecosystem indicators to variability in Antarctic krill. ICES J Mar Sci 62:366-373

Rice JC, Rochet MJ (2005) A framework for selecting a suite of indicators for fisheries management. ICES J Mar Sci 62:516-527

Rogers SI, Greenaway B (2005) A UK perspective on the development of marine ecosystem indicators. Mar Pollut Bull 50:9-19

Wanless S, Wright PJ, Harris MP, Elston DA (2004) Evidence for decrease in size of lesser sandeels Ammodytes marinus in a North Sea aggregation over a 30 -yr period. Mar Ecol Prog Ser 279:237-246

Submitted: August 30, 2006; Accepted: March 18, 2007 Proofs received from author(s): September 19, 2007 